\title{
Biomarkers and therapeutic targets: microRNA roles in the pathophysiology, diagnosis and management of eosinophilic esophagitis
}

\author{
Kristin A. Lambert ${ }^{1,2,3}$, Punit Jhaveri ${ }^{4}$, Pooja Jhaveri ${ }^{5}$ \\ 'Department of Medicine, Division of Pulmonary, Allergy and Critical Care Medicine, Penn State Milton S. Hershey Medical Center, \\ Hershey, PA 17033, USA. \\ 2Department of Biochemistry and Molecular Biology, Penn State College of Medicine, Hershey, PA 17033, USA. \\ ${ }^{3}$ Medical Scientist Training Program, Penn State College of Medicine, Hershey, PA 17033, USA. \\ ${ }^{4}$ Department of Pediatrics, Division of Gastroenterology, Penn State Children's Hospital, Hershey, PA 17033, USA. \\ ${ }^{5}$ Department of Pediatrics, Division of Allergy \& Immunology, Penn State Children's Hospital, Hershey, PA 17033, USA
}

Correspondence to: Dr. Pooja Jhaveri, Division of Allergy \& Immunology, Penn State Health, 500 University Drive, Hershey, PA 17033, USA.E-mail: pjhaveri@pennstatehealth.psu.edu

How to cite this article: Lambert KA, Jhaveri P, Jhaveri P. Biomarkers and therapeutic targets: microRNA roles in the pathophysiology, diagnosis and management of eosinophilic esophagitis. J Trans/Genet Genom 2018;2:11. https://doi.org/10.20517/jtgg.2018.11

Received: 4 Jun 2018 First Decision: 18 Jun 2018 Revised: 7 Jul 2018 Accepted: 19 Jul 2018 Published: 8 Aug 2018

Science Editor: Faoud Terrence Ishmael Copy Editor: Jun-Yao Li Production Editor: Huan-Liang Wu

\begin{abstract}
Eosinophilic esophagitis (EoE) is a chronic inflammatory disease that is increasingly recognized as the cause of common gastrointestinal symptoms including dysphagia, chest and abdominal pain, heartburn, food impaction, and food refusal in children and adults. Often referred to as "asthma of the esophagus", eosinophilic esophagitis, like its asthma counterpart, is an allergic disorder on the rise worldwide. Clinically managed by food avoidance, steroid therapy, recurring endoscopic evaluations and dilations as needed, eosinophilic esophagitis is a poorly understood disease process with limited therapies and even fewer diagnostic tools to predict and surveil active inflammation. As a result, there is a critical need to identify noninvasive biomarkers and therapeutic targets for eosinophilic esophagitis. Here we review the known contributions of miRNAs to eosinophilic inflammation of the esophagus and the potential for miRNA biomarkers for EoE in the clinical setting.
\end{abstract}

Keywords: Eosinophilic esophagitis, microRNA, miR-375, miR-21, miR-223, biomarkers, miRNA replacement therapy

\section{INTRODUCTION}

Eosinophilic esophagitis (EoE) is an emerging allergic disease worldwide and a leading cause of dysphagia and food impaction in children and adults ${ }^{[1-5]}$. A progressive fibrostenotic disease, EoE is an antigen-driven, non-IgE mediated, inflammatory process affecting the esophagus ${ }^{[6]}$. EoE is characterized by eosinophil-rich

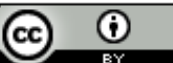

(c) The Author(s) 2018. Open Access This article is licensed under a Creative Commons Attribution 4.0 International License (https://creativecommons.org/licenses/by/4.0/), which permits unrestricted use, sharing, adaptation, distribution and reproduction in any medium or format, for any purpose, even commercially, as long as you give appropriate credit to the original author(s) and the source, provide a link to the Creative Commons license, and indicate if changes were made. 


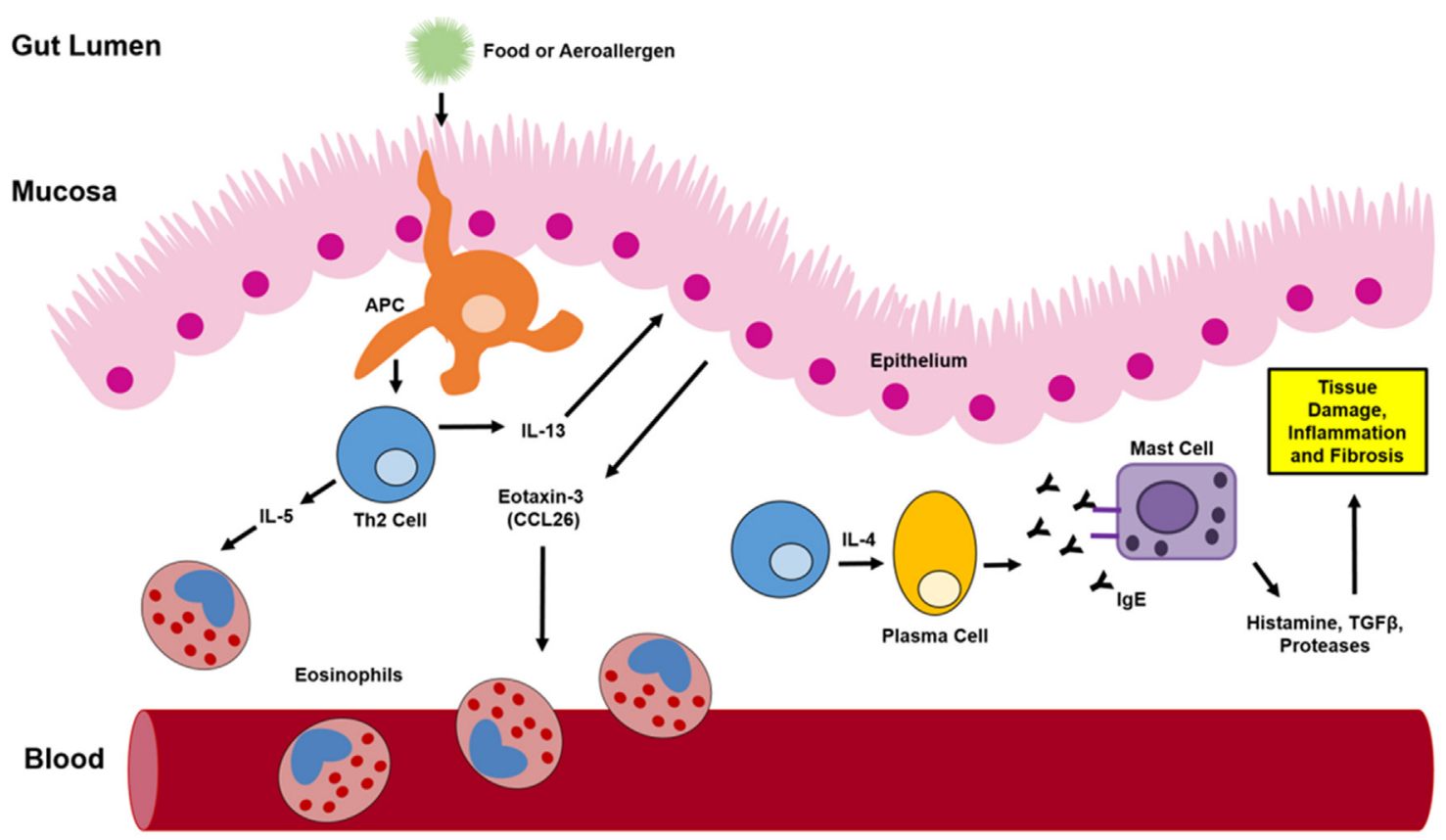

Figure 1. Pathophysiology of eosinophilic esophagitis. Barrier integrity is essential in the gastrointestinal tract to protect against inappropriate inflammation. Impaired barrier defenses and allergic sensitization to food and aeroallergens can then initiate inflammation in the esophageal epithelium. Tissue resident antigen-presenting cells are thought to process and present allergenic peptides to CD4+ T lymphocytes, activating and skewing T cell differentiation towards T helper type 2 (Th2) lymphocyte development. When activated by antigen, Th2 cells produce pathogenic and inflammatory cytokines, IL-13, IL-5, and IL-4. IL-13 induces non-traditional immune cells, like the epithelium, to produce chemoattractant cytokines. One chemokine, CCL26 (also called Eotaxin-3) attracts and recruits eosinophils to the esophageal tissue. IL-5 promotes eosinophil maturation, differentiation, and activation, leading to the release of allergic mediators. IL-4 activates B cells to differentiate into plasma cells, undergo class switching, and produce antigen-specific lgE. IgE can then bind to Fc receptors on mast cells, triggering degranulation and release of histamine and proteases. Activated mast cells also produce TGF- $\beta$, a key cytokine implicated in fibrotic processes that lead to stenotic disease and esophageal narrowing

gastrointestinal inflammation in the absence of other underlying causes of eosinophilia such as parasitic infection, inflammatory bowel disease, celiac disease, drug hypersensitivity, malignancy, graft- $v$-host disease, connective tissues disease and autoimmune disorders ${ }^{[7,8]}$. Although the etiology of EoE is still under active investigation, aeroallergen and food antigen exposure are known to trigger inflammation ${ }^{[9-11]}$. In fact, an allergic origin for EoE is supported by a close association with comorbid atopic diseases such as eczema, food allergy, asthma and allergic rhinitis ${ }^{[12]}$. Fresh insights also suggest that EoE may be a late manifestation of "atopic march" $"$ "13].

The pathophysiology of EoE is marked by immune cell infiltration of the esophageal epithelium and mucosa by eosinophils and other leukocytes (B cells, T cells, and activated mast cells) ${ }^{[14]}$. These immune cells are capable of producing Th2 cytokines and eotaxin family chemokines that sustain chronic inflammation [Figure 1$]^{[15]}$. Ultimately, inflammation leads to narrowing of the esophageal lumen and symptoms of solidfood and liquid dysphagia, chest pain, food impaction, acid-reflux and even feeding disorders in children ${ }^{[14,16]}$. While symptoms are currently managed by dietary elimination of offending foods, swallowed steroids, or some combination of both, there are no FDA-approved treatments that currently exist for EoE. Consequently, there is a need to identify novel therapeutics and biomarkers to guide therapy.

MicroRNA (miRNAs) are small regulatory molecules active in the control of 30\%-60\% of the human genome ${ }^{[17]}$. These small genetic elements are also readily detectable in almost all known bodily fluids and tissues ${ }^{[18,19]}$. Accordingly, miRNAs have emerged as biomarker candidates and putative targets for anti-inflammatory and immunomodulatory therapies. A mounting body of work has described miRNA expression and function in many allergic diseases, including asthma ${ }^{[20-23]}$, atopic dermatitis ${ }^{[24,25]}$, and allergic rhinitis ${ }^{[21,26]}$. 


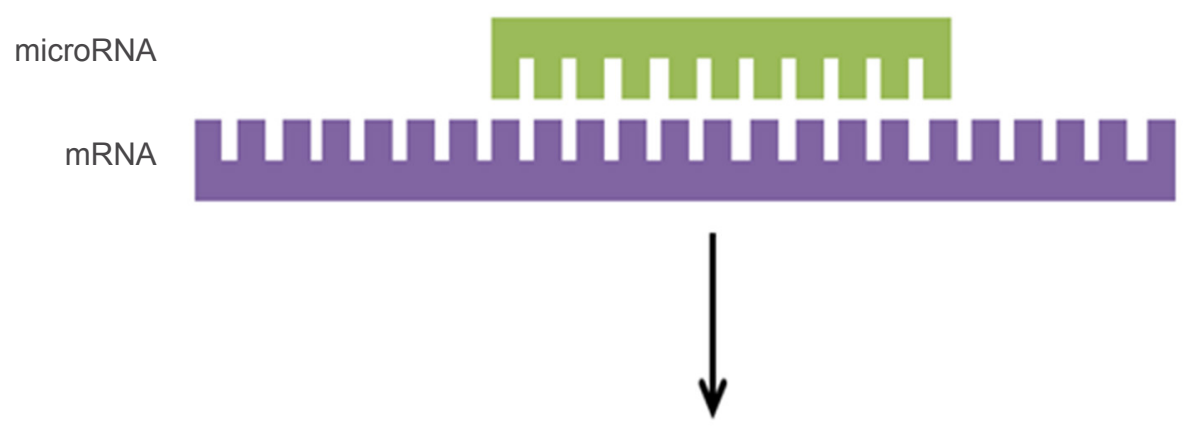

Translational repression or degradation of mRNA

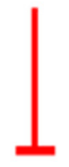

Protein synthesis

Figure 2. Post-transcriptional regulation of target mRNAs by microRNAs. microRNAs bind to complementary sequences on target messenger RNAs and promote degradation of the nascent transcript before it can be translated into protein

However, to date only three studies have reported on miRNA expression in EoE and fewer still have commented on the function of miRNAs in eosinophilic esophagitis pathogenesis. This review discusses our current understanding of miRNA roles in eosinophilic esophagitis, offers insights into miRNA potential for clinical utility, and comments on future investigations.

\section{MIRNA CONTRIBUTIONS TO NORMAL ESOPHAGEAL FUNCTION}

First identified in 1977, EoE was originally thought to be a variant of gastroenteritis and was only later identified as a distinct clinical entity ${ }^{[27]}$. Nearly three decades later, microRNAs were unearthed as immunoregulatory molecules and pathogenic contributors to the inflammation in EoE. miRNAs are small noncoding RNAs, approximately 12-22 nucleotides in length, that participate in post-transcriptional gene silencing of targets. Binding of miRNAs with complementary base pairs in the $3^{\prime}$ untranslated region (UTR) of mRNA transcripts leads to inhibition of target gene expression or protein [Figure 2].

miRNAs have homeostatic roles in normal cellular processes in all cells and tissues. In the gastrointestinal epithelium, miRNAs have been shown to regulate aspects of mucosal immunity and barrier response ${ }^{[28,29]}$. For example, miR-34a and miR-365 have roles in the maturation of gut-associated lymphoid tissue (GALT). miR-34a has been shown to downregulate members of the Notch1 signaling pathway that control normal differentiation of $\mathrm{M}$ cells, a highly specialized epithelial cell ${ }^{[30]}$. In this way, repression of Notch-1 signaling by miR-34a leads to normal development of structures at the mucosal interface that sample antigen and initiate immune responses. Likewise, repression of miR-365's target gene, Myb-related protein B (MYBL2) is necessary for colonic epithelium to fully differentiate. Deregulation of miRNA pathways or alterations in miRNA expression in tissue can then perturb homeostasis and lead to disease conditions like eosinophilic inflammation in the esophagus.

\section{DYSREGULATION OF MIRNAS IN INFLAMED TISSUE DIFFERENTIATES EOE FROM HEALTHY ESOPHAGI}

In 2012, Lu et al. ${ }^{[31]}$ uncovered the first evidence of a unique, miRNA signature in diseased esophageal tissue 
Table 1. miRNAs differentially expressed in EoE esophageal tissue compared to healthy controls

\begin{tabular}{|c|c|}
\hline microRNA & Esophageal expression (EoE vs, healthy) \\
\hline miR-7 & Increased ${ }^{\dagger}$ \\
\hline miR-15a & Increased $\mathrm{d}^{\#}$ \\
\hline miR-20a & Increased $d^{\#}$ \\
\hline miR-21 & Increased ${ }^{1 / \#}$ \\
\hline $\operatorname{miR}-29 a$ & Increased ${ }^{\#}$ \\
\hline miR-29b & Increased ${ }^{\dagger}$ \\
\hline miR-92a & Increased \\
\hline miR-106b & Increased ${ }^{\dagger, \#}$ \\
\hline miR-126 & Increased ${ }^{\#}$ \\
\hline miR-132 & Increased ${ }^{\dagger}$ \\
\hline miR-142-5p & Increased ${ }^{\#}$ \\
\hline miR-142-3p & Increased ${ }^{\dagger, \#}$ \\
\hline miR-212 & Increased ${ }^{\dagger}$ \\
\hline miR-221 & Increased $\#$ \\
\hline $\operatorname{miR}-222$ & Increased $^{\dagger}$ \\
\hline miR-223 & Increased"\# \\
\hline miR-339-5p & Increased ${ }^{\dagger}$ \\
\hline miR-592 & Increased \\
\hline miR-642 & Increased ${ }^{\dagger}$ \\
\hline miR-801 & Increased ${ }^{\dagger}$ \\
\hline miR-886-5p or $3 p$ & Increased ${ }^{\dagger}$ \\
\hline Let-7c & Decreased $^{\dagger}$ \\
\hline miR-30-3p & Decreased $^{\dagger}$ \\
\hline miR-99a & Decreased ${ }^{\sharp}$ \\
\hline $\operatorname{miR}-144$ & Decreased $^{\dagger}$ \\
\hline miR-193a-5p and 3p & Decreased $^{\dagger}$ \\
\hline miR-193b & Decreased $^{\dagger}$ \\
\hline miR-203 & Decreased ${ }^{\dagger, \#}$ \\
\hline miR-210 & Decreased ${ }^{\dagger \#}$ \\
\hline miR-211 & Decreased $^{\dagger}$ \\
\hline miR-365 & Decreased $^{\dagger}$ \\
\hline miR-375 & Decreased $^{\dagger}$ \\
\hline
\end{tabular}

miRNA expression data is from the following studies: 'Lu et al. ${ }^{[32]}, "$ Zahm et al. ${ }^{[33]}$

from EoE patients. The authors subsequently completed in-depth molecular profiling of esophageal epithelial miRNA expression and identified 32 differentially regulated miRNAs between individuals with EoE and healthy control subjects. Among these targets [Table 1], miR-375 was the most downregulated and miR21 and miR-223 were the most upregulated in EoE tissue ${ }^{[32]}$. Similarly, the Zahm study in $2014^{[33]}$ identified 14 miRNAs that are differentially expressed between EoE and healthy subjects, 6 of which were previously identified by Lu et al. ${ }^{[32]}$ in 2012. The additional 8 miRNAs identified by Zahm et al. ${ }^{[33]}$, not seen in Lu et al. ${ }^{[32]}$ in 2012, could be more specific to early stages of EoE, as their study utilized a pediatric cohort. Common to both studies, miR-375, miR-21 and miR-223 emerged as central candidates for EoE biomarkers and therapeutic targets.

\section{miR-375 deficiency in esophageal epithelium of EoE patients}

Through miRNA microarrays, Lu et al. ${ }^{[32]}$ identified miR-375 as the only miRNA differentially regulated in epithelial cell lines in response to Th2 cytokine, IL-13. This preliminary work indicated that esophageal expression of miR-375 was inversely correlated with allergic inflammation and disease. While esophageal levels of miR-375 were low in EoE, they associated with high levels of inflammation. The same year, the authors also reported in a second study that esophageal levels of miR-375 reverse with treatment. miR-375 increases in the esophagus, normalizing to levels comparable to healthy individuals, in adult EoE patients in remission 


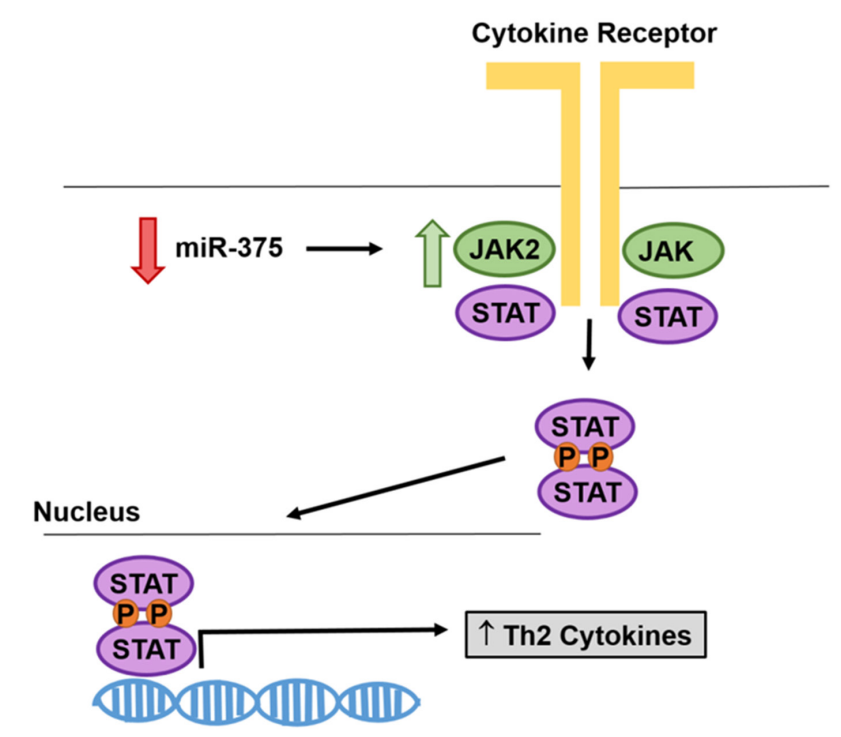

Figure 3. Decreased miR-375 in EoE tissue may relieve inhibition of JAK2, promoting cytokine signaling. miRWalk 2.0 predicted that miR375 can bind to and target JAK2 for degradation.. Based on data from esophageal biopsies, individuals with EoE have lower levels of miR375 than their healthy counterparts. While miR-375 may normally exist to inhibit JAK2 and dampen cytokine signaling, a lack of miR-375 may remove this negative regulation allowing for more cytokine signaling to occur in EoE

on either elimination diet or fluticasone steroid ${ }^{[32]}$. Collectively, both studies implicate miR-375 as an effective EoE biomarker, accurately reflecting disease activity ${ }^{[31,32]}$.

These findings were further substantiated by a study in 2014 that profiled miRNA expression in esophageal biopsies of pediatric patients with $\mathrm{EoE}^{[33]}$. Zahm et al ${ }^{[33]}$ observed in their pediatric cohort that esophageal expression of miR-375 was also lower in EoE individuals compared to healthy controls. Similar to adult studies, miR-375 expression inversely correlated with inflammation. Children with low miR-375 had increased Th2 cytokines (IL-5 and IL-13) and mast-cell specific gene (CPA3 and TPSAB1) expression. Based on miRWalk2.0's predictive algorithm, miR-375 is not expected to bind to IL-5, IL-13, CPA3 and TPSAB1 ${ }^{[34]}$. As a result, these Th2 cytokines are unlikely to be the direct targets of miR-375 activity and unlikely to constitute the mechanism by which miR-375 regulates esophageal inflammation. It seems more likely based on predictive algorithms that miR-375 regulates JAK2, a critical intercellular member of JAK/STAT-mediated cy tokine signaling pathways ${ }^{[34]}$. Studies by Lu et al ${ }^{[31,32]}$ and Zahm et al ${ }^{[33]}$ all similarly identify a deficiency of miR375 in diseased esophageal tissue that could, in theory, relieve inhibition on JAK2 and promote increased signaling of Th2 cytokine pathways [Figure 3].

\section{Abundance of miR-21 and miR-223 in esophageal epithelium associated with inflammation}

In addition to miR-375, Zahm et al. ${ }^{[33]}$ and Lu et al. ${ }^{[32]}$ also found that miR-21, miR-223 were differentially expressed in EoE tissue. In contrast to miR-375, both miR-21 and miR-223 were upregulated or present in high levels in esophageal biopsies of EoE subjects. Lu et al ${ }^{[32]}$ conducted genome-wide expression correlation analysis which showed that miRNAs, miR-21 and miR-223, co-regulate genes involved in immune regulation. More specifically, miR-21 and miR-223 control processes such as T cell polarization (Th1 vs. Th2), IFNgamma signaling and eosinophilia ${ }^{[32]}$. miR-21 in particular has been shown in mouse models of allergic inflammation and human disease to post-transcriptionally regulate a subunit of the IL-12 cytokine (IL-12p35). By binding to the 3' UTR of the IL-12p35 transcript, miR-21 can degrade IL-12-p35, inhibiting its action in promotingTh1 immunity [Figure 4]. In this way, miR-21 inhibition of IL-12 shifts T cell polarization towards Th2 immunity associated with allergic diseases ${ }^{[22]}$. Consistent with this observation in allergic airway inflammation, Lu et al ${ }^{[32]}$ also noted likely miR-21 inhibition of IL-12p35 in the esophageal biopsies of EoE pa- 
Table 2. Key miRNAs in EoE, their predicted targets and anticipated phenotypic changes as a result

\begin{tabular}{llll}
\hline microRNA & $\begin{array}{c}\text { Esophageal expression } \\
\text { (EoE vs, healthy) }\end{array}$ & mRNA target & Phenotype \\
\hline miR-375 & Decreased expression & CXCL12; JAK2; MMD & $\begin{array}{l}\text { Increased lymphocyte chemotaxis; increased JAK/stat-mediat- } \\
\text { ed cytokine signaling; increased macrophage differentiation }\end{array}$ \\
miR-21 & Increased expression & IL-12 & Promotes Th2 type inflammation in the esophagus \\
miR-223 & Increased expression & SPINK7 & Destruction and impairment of the epithelial barrier \\
\hline
\end{tabular}

Online bioinformatics database, miRWalk 2.0, was used to predict biologic targets of miRNAs that have yet to be validated in vitro or in vivo $^{[34]}$. Relevant targets involved in inflammatory, immune and barrier function are listed

tients. High levels of miR-21 in the esophagus of EoE patients correlated with decreased IL-12p35, suggesting a tendency towards Th2 or allergic inflammation in EoE tissue.

Unlike miR-21, which has been actively investigated in numerous types of inflammatory and immune mediated diseases, miR-223 action and targets are not known. Although targets of miR-223 have not be identified in vitro or in vivo, mRNAs that may be bound by miR-223 were predicted by our group through bioinformatic software miRWalk 2.0 [Table 2]. Serine protease inhibitor, SPINK7, was predicted as a direct target of miR-223. Interestingly, a recent study led by Marc Rothenberg discovered that individuals with active EoE lack SPINK7 in their esophageal epithelium ${ }^{[35]}$. In vitro experiments in esophageal epithelial cell lines demonstrated that knockdown and knockout of SPINK7 disrupted barrier function and increased inflammatory cytokine production, suggesting that SPINK7 deficiency may contribute to EoE pathogenesis. Independent of this study, miR-223 has been shown to be upregulated in esophageal biopsies of EoE patients and our bioinformatics modeling predicts miR-223 can bind SPINK7. Taken together, these observations suggest a potential uninvestigated mechanism by which miR-223 exerts pathogenic effects in EoE [Figure 5]. Increased miR-223 in the epithelium may bind to the 3' UTR of SPINK7, depleting this key protective protein in the esophagus. SPINK7 deficiency ultimately leads to impaired barrier integrity and inflammation.

\section{MIRNA REPLACEMENT THERAPY WITH MIR-375}

In vitro experiments conducted by Lu et al. ${ }^{[31]}$ in 2012 showed relevance of miR-375 in the pathogenesis and treatment of EoE beyond biomarker capacity. Overexpression of miR-375 in esophageal epithelium downregulated a panel of IL-13 associated inflammatory genes pathogenic in eosinophilic esophagitis, including Th2 cytokines, and proteins involved in mast cell activation and eosinophil chemoattraction ${ }^{[31]}$. Taken together, transfection or "add back" of mir-375 into esophageal epithelium had anti-inflammatory function that inhibited allergic responses associated with EoE. This work suggests that miR-375 may be protective against EoE. In many fields like oncology, pharmaceutical and drug development efforts have trialed miRNA replacement therapy. This therapeutic strategy employs delivery of synthetic, double-stranded miRNA mimics, encased in lipid-based vectors to diseased tissue ${ }^{[36]}$. EoE esophageal tissue has been shown to be depleted of natural or endogenous miR-375, so oral administration of artificial miR-375 could be effective at restoring anti-inflammatory function missing in EoE patients.

miRNA-based immunotherapies are already under investigation for other inflammatory diseases of the gastrointestinal tract, so they may not be out of reach for EoE. Research in the inflammatory bowel disease field has begun to address potential limitations for RNA delivery to gastrointestinal tissue, accounting for the stability and protection of RNA in nanoparticles to successfully avoid degradation by ribonucleases, bile salts, pancreatic lipases and extreme $\mathrm{pH}$. Preliminary miRNA therapeutic work done in murine models of colitis show efficacy for delivering miRNAs to diseased tissue and exerting appreciable anti-inflammatory effects, decreasing cytokine expression and reducing disease scores on histology ${ }^{[37]}$. This encouraging work points towards future investigations of therapeutic oral administration of miR-375 for EoE. 


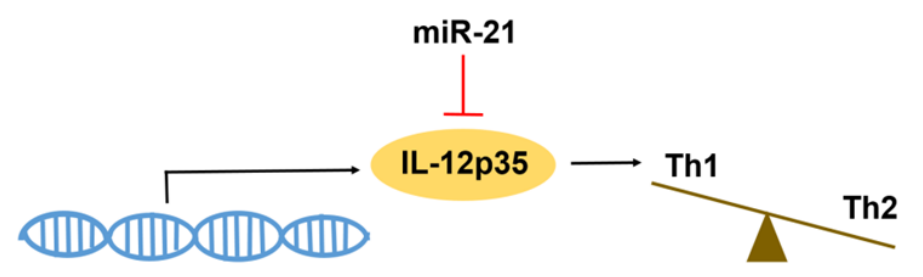

Figure 4. miR-21 regulates $T$ cell polarization through direct targeting of IL-12p35. IL-12p35 is one subunit of the IL-12 cytokine that promotes differentiation of naïve T cells towards T helper type 1 cells, instead of T helper type 2 . Through post-transcriptional regulation, miR-21 is able to inhibit IL-12p35, also inhibiting Th1 immunity and shifting T cell polarization and function towards T helper type 2

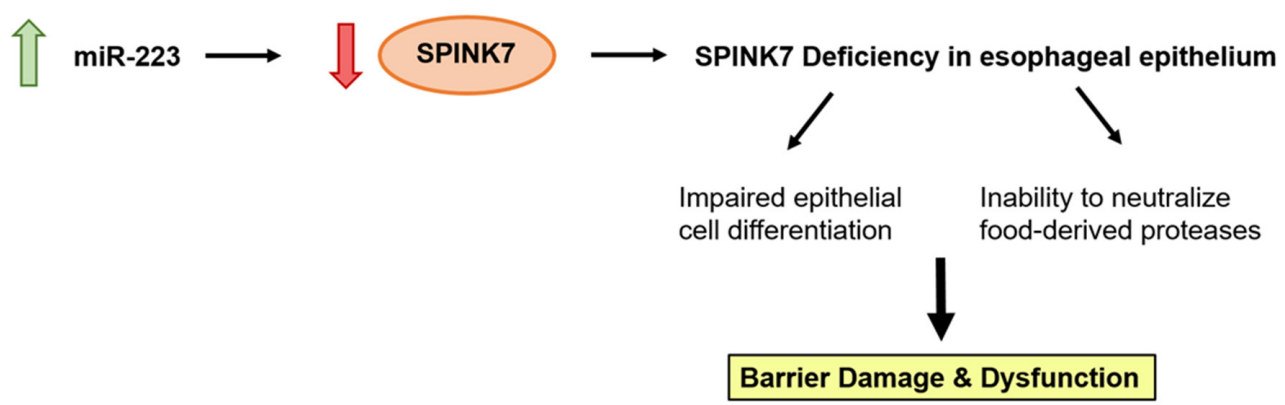

Figure 5. miR-223 is predicted to bind to the $3^{\prime}$ UTR of the transcript for protease inhibitor, SPINK7, leading to barrier damage and dysfunction in the esophageal epithelium. SPINK7 is required for normal epithelial cell differentiation and protection of the esophagus from harsh, food-derived proteases. miRWalk 2.0 predicts that miR-223 can target SPINK7 for degradation. A resulting deficiency of SPINK7 can lead to increased damage of the esophageal epithelium in EoE

\section{EXTRACELLULAR MIRNAS [PLASMA AND SALIVARY MIRNAS] AS NONINVASIVE BIOMARKERS}

The current standard of care for EoE patients is surveillance by esophagogastroduodenoscopy with biopsy. In children, recurrent endoscopy can be challenging, traumatic and a substantial financial burden for families and adult patients alike. These barriers necessitate a search for non-invasive diagnostics and biomarkers ${ }^{[38]}$. Dubbed a liquid biopsy, circulating or plasma miRNAs constitute one potential option for a non-invasive biomarker to monitor disease progression and responses to therapy. Work by T.X. Lu and colleagues in 2012 identified miR-146a, miR-146b and miR-223 as the most abundant circulating miRNAs in plasma differentially expressed between EoE and healthy individuals. Interestingly, miR-146a and miR-223 levels reverse in EoE patients who achieved remission with glucocorticoids; whereas, elevated miR-146b plasma levels persist with remission ${ }^{[32,39]}$. Not only are these miRNAs stable and detectable in the blood of human subjects, these findings also provide proof-of-concept for future clinical use of miRNAs as non-invasive biomarkers In Lu's study, miR-146a and miR-223 had positive predictive values of 0.82 and 0.77 and negative predictive values of 0.73 and 0.64 , respectively. Taken together, this work demonstrates that a simple blood draw with miRNA profiling could lead to rapid screening and sensitive detection of disease state and treatment responsiveness in EoE patients ${ }^{[32]}$. Moreover, this work is a promising alternative to recurrent, invasive endoscopies and biopsies that are the current standard of care. The lack of current diagnostic tools to assess inflammation and manage treatment of EoE patients necessitates further investigation of plasma miRNA biomarkers, specifically miR-146a and miR-223.

Saliva may be yet another source of biomarkers. Extracellular miRNAs are detectable in the oronasaopharyngeal cavity and can also be obtained non-invasively without endoscopy. Although limited, a few recent pilot studies hint at the potential to reliably detect different miRNAs signatures in saliva of EoE patients $v s$. controls ${ }^{[40,41]}$. Kelbel et al. ${ }^{[40]}$ analyzed miRNA expression in saliva samples from 15 adult patients with EoE and 17 healthy controls. They observed increased in miR-570-3p, miR-3613-5p, miR-4668-5p, and miR-30a- 
Table 3. Currently identified eosinophilic esophagitis endotypes

\begin{tabular}{|c|c|c|c|}
\hline Clinical features & Endotype 1 & Endotype 2 & Endotype 3 \\
\hline Endoscopic appearance & Normal & Inflammation & Fibrostenotic \\
\hline Steroid responsiveness & Sensitive & Refractory & Mixed responses \\
\hline Disease onset & No age Predominance & Pediatric & Adult \\
\hline Atopic status & Atopic & No clear association with atopy & Non-atopic \\
\hline
\end{tabular}

Molecular profiling of esophageal biopsies from a recent cohort of nearly 200 adult and pediatric patients was correlated with other clinical features of EoE in order to identify three clusters or distinct groups of disease. The three groups or endotypes range in severity from mild (Endotype 1) to severe (Endotype 3) ${ }^{[42]}$

$5 p$ in EoE samples compared to control. Expression of miR-3613-5p and miR-4668-5p decreased in patients following fluticasone treatment, suggesting these two miRNAs may be candidate biomarkers for surveilling treatment response ${ }^{[40]}$. Similarly, Swanson et al. ${ }^{[41]}$ profiled salivary miRNA in a pediatric cohort and discovered 97 differentially expressed miRNAs, with miR-223 having the greatest level of expression. Here too, Swanson et al. ${ }^{[41]}$ demonstrate the potential for identifying noninvasive miRNA biomarkers in saliva.

\section{FUTURE PERSPECTIVES AND CONCLUSIONS}

Our understanding of miRNA contributions to inflammation and the regulation of immune function has improved but still remains underdeveloped. In particular, there are many unanswered questions regarding the role of miRNAs in eosinophilic esophagitis. Recent work has defined three main disease endotypes [Table 3] that associate with phenotypic and clinical features of $\mathrm{EoE}^{[42]}$. These newly identified EoE endotypes have not yet been correlated with miRNA expression. It stands to be seen whether miRNAs are differentially expressed between EoE endotypes and whether miRNAs can then be used to predict disease course and treatment responsiveness for these subpopulations of disease. Similarly, the effects of dietary modification, acid suppression, and emerging biologic therapies on miRNA profiles in EoE are also under investigation. Future work that compares miRNA expression among growing cohorts of individuals with EoE may uncover distinct 'miRNA fingerprints' to guide effective and personalized treatment.

\section{DECLARATIONS}

\section{Authors' contributions}

Literature research: Lambert KA, Jhaveri P

Manuscript writing and figures: Lambert KA

Manuscript editing: Jhaveri $\mathrm{P}$, Jhaveri $\mathrm{P}$

Manuscript revision: Lambert KA, Jhaveri P, Jhaveri $\mathrm{P}$

\section{Availability of data and materials}

Not applicable.

\section{Financial support and sponsorship}

None.

\section{Conflicts of interest}

All authors declare that there are no conflicts of interest.

\section{Ethical approval and consent to participate}

Not applicable.

\section{Consent for publication}

Not applicable. 


\section{Copyright}

(C) The Author(s) 2018.

\section{REFERENCES}

1. Desai TK, Stecevic V, Chang CH, Goldstein NS, Badizadegan K, Furuta GT. Association of eosinophilic inflammation with esophageal food impaction in adults. Gastrointest Endosc 2005;61:795-801.

2. Kerlin P, Jones D, Remedios M, Campbell C. Prevalence of eosinophilic esophagitis in adults with food bolus obstruction of the esophagus. J Clin Gastroenterol 2007;41:356-61.

3. Sperry SL, Crockett SD, Miller CB, Shaheen NJ, Dellon ES. Esophageal foreign-body impactions: epidemiology, time trends, and the impact of the increasing prevalence of eosinophilic esophagitis. Gastrointest Endosc 2011;74:985-91.

4. Mahesh VN, Holloway RH, Nguyen NQ. Changing epidemiology of food bolus impaction: is eosinophilic esophagitis to blame? J Gastroenterol Hepatol 2013;28:963-6.

5. Dellon ES, Hirano I. Epidemiology and natural history of eosinophilic esophagitis. Gastroenterology 2018;154:319-32.e3.

6. Simon D, Cianferoni A, Spergel JM, Aceves S, Holbreich M, Venter C, Rothenberg ME, Terreehorst I, Muraro A, Lucendo AJ, Schoepfer A, Straumann A, Simon HU. Eosinophilic esophagitis is characterized by a non-IgE-mediated food hypersensitivity. Allergy 2016;71:611-20.

7. DeBrosse CW, Rothenberg ME. Allergy and eosinophil-associated gastrointestinal disorders (EGID). Curr Opin Immunol 2008;20:703-8.

8. Sampson HA, Aceves S, Bock SA, James J, Jones S, Lang D, Nadeau K, Nowak-Wegrzyn A, Oppenheimer J, Perry TT, Randolph C, Sicherer SH, Simon RA, Vickery BP, Wood R, Joint Task Force on Practice Parameters, Bernstein D, Blessing-Moore J, Khan D, Lang D, Nicklas R, Oppenheimer J, Portnoy J, Randolph C, Schuller D, Spector S, Tilles SA, Wallace D, Practice Parameter Workshop, Sampson HA, Aceves S, Bock SA, James J, Jones S, Lang D, Nadeau K, Nowak-Wegrzyn A, Oppenheimer J, Perry TT, Randolph C, Sicherer SH, Simon RA, Vickery BP, Wood R. Food allergy: a practice parameter update-2014. J Allergy Clin Immunol 2014;134:1016-25.e43.

9. Fogg MI, Ruchelli E, Spergel JM. Pollen and eosinophilic esophagitis. J Allergy Clin Immunol 2003;112:796-7.

10. Rayapudi M, Mavi P, Zhu X, Pandey AK, Abonia JP, Rothenberg ME, Mishra A. Indoor insect allergens are potent inducers of experimental eosinophilic esophagitis in mice. J Leukoc Biol 2010;88:337-46.

11. Lucendo AJ, Molina-Infante J, Arias A, von Arnim U, Bredenoord AJ, Bussmann C, Amil Dias J, Bove M, Gonzalez-Cervera J, Larsson H, Miehlke S, Papadopoulou A, Rodriguez-Sanchez J, Ravelli A, Ronkainen J, Santander C, Schoepfer AM, Storr MA, Terreehorst I, Straumann A, Attwood SE. Guidelines on eosinophilic esophagitis: evidence-based statements and recommendations for diagnosis and management in children and adults. United European Gastroenterol J 2017;5:335-58.

12. Wechsler JB, Bryce PJ. Allergic mechanisms in eosinophilic esophagitis. Gastroenterol Clin North Am 2014;43:281-96.

13. Hill DA, Grundmeier RW, Ramos M, Spergel JM. Eosinophilic esophagitis is a late manifestation of the atopic march. J Allergy Clin Immunol 2018; doi: 10.1016/j.jaip.2018.05.010.

14. Hill DA, Spergel JM. The immunologic mechanisms of eosinophilic esophagitis. Curr Allergy Asthma Rep 2016;16:9.

15. O'Shea KM, Aceves SS, Dellon ES, Gupta SK, Spergel JM, Furuta GT, Rothenberg ME. Pathophysiology of eosinophilic esophagitis. Gastroenterology 2018;154:333-45.

16. Mishra A, Hogan SP, Brandt EB, Rothenberg ME. An etiological role for aeroallergens and eosinophils in experimental esophagitis. J Clin Invest 2001;107:83-90.

17. Friedman RC, Farh KK, Burge CB, Bartel DP. Most mammalian mRNAs are conserved targets of microRNAs. Genome Res 2009;19:92105.

18. Cortez MA, Bueso-Ramos C, Ferdin J, Lopez-Berestein G, Sood AK, Calin GA. MicroRNAs in body fluids--the mix of hormones and biomarkers. Nat Rev Clin Oncol 2011;8:467-77.

19. Weber JA, Baxter DH, Zhang S, Huang DY, Huang KH, Lee MJ, Galas DJ, Wang K. The microRNA spectrum in 12 body fluids. Clin Chem 2010;56:1733-41.

20. Panganiban RP, Pinkerton MH, Maru SY, Jefferson SJ, Roff AN, Ishmael FT. Differential microRNA epression in asthma and the role of miR-1248 in regulation of IL-5. Am J Clin Exp Immunol 2012;1:154-65.

21. Panganiban RP, Wang Y, Howrylak J, Chinchilli VM, Craig TJ, August A, Ishmael FT. Circulating microRNAs as biomarkers in patients with allergic rhinitis and asthma. J Allergy Clin Immunol 2016;137:1423-32.

22. Lu TX, Munitz A, Rothenberg ME. MicroRNA-21 is up-regulated in allergic airway inflammation and regulates IL-12p35 expression. J Immunol 2009;182:4994-5002.

23. Liu F, Qin HB, Xu B, Zhou H, Zhao DY. Profiling of miRNAs in pediatric asthma: upregulation of miRNA-221 and miRNA-485-3p. Mol Med Rep 2012;6:1178-82.

24. Sonkoly E, Janson P, Majuri ML, Savinko T, Fyhrquist N, Eidsmo L, Xu N, Meisgen F, Wei T, Bradley M, Stenvang J, Kauppinen S, Alenius H, Lauerma A, Homey B, Winqvist O, Stahle M, Pivarcsi A. MiR-155 is overexpressed in patients with atopic dermatitis and modulates T-cell proliferative responses by targeting cytotoxic T lymphocyte-associated antigen 4. J Allergy Clin Immunol 2010;126:581-9.e1-20.

25. Vennegaard MT, Bonefeld CM, Hagedorn PH, Bangsgaard N, Lovendorf MB, Odum N, Woetmann A, Geisler C, Skov L. Allergic contact dermatitis induces upregulation of identical microRNAs in humans and mice. Contact Dermatitis 2012;67:298-305.

26. Shaoqing Y, Ruxin Z, Guojun L, Zhiqiang Y, Hua H, Shudong Y, Jie Z. Microarray analysis of differentially expressed microRNAs in allergic rhinitis. Am J Rhinol Allergy 2011;25:e242-6.

27. Attwood SE, Smyrk TC, Demeester TR, Jones JB. Esophageal eosinophilia with dysphagia. A distinct clinicopathologic syndrome. Dig Dis Sci 1993;38:109-16.

28. Biton M, Levin A, Slyper M, Alkalay I, Horwitz E, Mor H, Kredo-Russo S, Avnit-Sagi T, Cojocaru G, Zreik F, Bentwich Z, Poy MN, Artis D, Walker MD, Hornstein E, Pikarsky E, Ben-Neriah Y. Epithelial microRNAs regulate gut mucosal immunity via epithelium-T cell crosstalk. 
Nat Immunol 2011;12:239-46.

29. McKenna LB, Schug J, Vourekas A, McKenna JB, Bramswig NC, Friedman JR, Kaestner KH. MicroRNAs control intestinal epithelial differentiation, architecture, and barrier function. Gastroenterology 2010;139:1654-64.e1.

30. Nakato G, Hase K, Sato T, Kimura S, Sakakibara S, Sugiyama M, Obata Y, Hanazato M, Iwanaga T, Ohno H. Epithelium-intrinsic microRNAs contribute to mucosal immune homeostasis by promoting M-cell maturation. PLoS One 2016;11:e0150379.

31. Lu TX, Lim EJ, Wen T, Plassard AJ, Hogan SP, Martin LJ, Aronow BJ, Rothenberg ME. MiR-375 is downregulated in epithelial cells after IL-13 stimulation and regulates an IL-13-induced epithelial transcriptome. Mucosal Immunol 2012;5:388-96.

32. Lu TX, Sherrill JD, Wen T, Plassard AJ, Besse JA, Abonia JP, Franciosi JP, Putnam PE, Eby M, Martin LJ, Aronow BJ, Rothenberg ME. MicroRNA signature in patients with eosinophilic esophagitis, reversibility with glucocorticoids, and assessment as disease biomarkers. J Allergy Clin Immunol 2012;129:1064-75.e9.

33. Zahm AM, Menard-Katcher C, Benitez AJ, Tsoucas DM, Le Guen CL, Hand NJ, Friedman JR. Pediatric eosinophilic esophagitis is associated with changes in esophageal microRNAs. Am J Physiol Gastrointest Liver Physiol 2014;307:G803-12.

34. Dweep H, Gretz N. miRWalk2.0: a comprehensive atlas of microRNA-target interactions. Nat Methods 2015;12:697.

35. Azouz NP, Ynga-Durand MA, Caldwell JM, Jain A, Rochman M, Fischesser DM, Ray LM, Bedard MC, Mingler MK, Forney C, Eilerman M, Kuhl JT, He H, Biagini Myers JM, Mukkada VA, Putnam PE, Khurana Hershey GK, Kottyan LC, Wen T, Martin LJ, Rothenberg ME. The antiprotease SPINK7 serves as an inhibitory checkpoint for esophageal epithelial inflammatory responses. Sci Transl Med 2018;10:eaap9736.

36. Anthiya S, Griveau A, Loussouarn C, Baril P, Garnett M, Issartel JP, Garcion E. MicroRNA-based drugs for brain tumors. Trends Cancer 2018;4:222-38.

37. Guo J, Jiang X, Gui S. RNA interference-based nanosystems for inflammatory bowel disease therapy. Int J Nanomedicine 2016;11:5287310 .

38. Aceves SS. Unmet therapeutic needs in eosinophilic esophagitis. Dig Dis 2014;32:143-8.

39. Lu S, Mukkada VA, Mangray S, Cleveland K, Shillingford N, Schorl C, Brodsky AS, Resnick MB. MicroRNA profiling in mucosal biopsies of eosinophilic esophagitis patients pre and post treatment with steroids and relationship with mRNA targets. PLoS One 2012;7:e40676.

40. Kelbel TE, Ghaffari G, Sena M, Ishmael FT. Salivary microRNA as a biomarker for monitoring response to treatment in eosinophilic esophagitis. J Allergy Clin Immunol 2015;135:AB78.

41. Swanson K, Devaraj, S., Shulman, R., Schaefer, J., Hiremath, G. . Salivary microRNAs in eosinophilic esophagitis: pathobiologic implications and potential as noninvasive biomarker. Gastroenterology 2016;150:S673-S4.

42. Shoda T, Wen T, Aceves SS, Abonia JP, Atkins D, Bonis PA, Caldwell JM, Capocelli KE, Carpenter CL, Collins MH, Dellon ES, Eby MD, Gonsalves N, Gupta SK, Falk GW, Hirano I, Menard-Katcher P, Kuhl JT, Krischer JP, Leung J, Mukkada VA, Spergel JM, Trimarchi MP, Yang GY, Zimmermann N, Furuta GT, Rothenberg ME; Consortium of Eosinophilic Gastrointestinal Disease Researchers (CEGIR). Eosinophilic oesophagitis endotype classification by molecular, clinical, and histopathological analyses: a cross-sectional study. Lancet Gastroenterol Hepatol 2018;3:477-88. 